\title{
CIVILIZACIÓN, CULTURA Y BARBARIE DESDE LOS FUNDAMENTOS DE LA TECTÓNICA DE PLACAS
}

\author{
Civilization, Culture and Barbarism on the Basis of Plate Tectonics
}

\author{
Guillermo Aguirre Martínez \\ guillermo-aguirre@hotmail.com \\ Universidad Internacional de Valencia. España \\ Fecha de recepción: 11/12/2019 \\ Fecha de aceptación: 11/04/2020
}

Resumen: En este trabajo se considerarán aspectos relativos a los conceptos de cultura, civilización, símbolo y barbarie. Comprendemos que, lejos de emplear estos términos como campo de batalla de una actitud por lo común encubridora de una postura ideológica, conviene despojarlos de dichas connotaciones y centrarnos en explorar su significación elemental. Prestar atención al revés o negativo de dichos términos resulta revelador al respecto.

Palabras clave: cultura; civilización; símbolo; barbarie.

Abstract: We will discuss about aspects near to the concepts of 'culture', 'civilization', 'symbol' and 'barbarism'. We understand that the best way to study this topic is to observe the bond between all these words -culture, civilization, symbol and barbarism- and, in parallel, to divest them of ideological connections. Furthermore, we will explore the back or negative of these concepts: from this perspective, we can illuminate other aspects of the current matter.

Keywords: Culture; Civilization; Symbol; Barbarism.

SUMARIO: 1. Introducción. 2. Modelos hipotéticos. 3. En torno al límite y al símbolo. 4. Sincretismo. 5. Inflación y devaluación simbólica. 6. Conclusiones. 7. Referencias bibliográficas. 


\section{INTRODUCCIÓN}

A la hora de realizar una apreciación sobre la cultura tendemos a vincularla con la actividad estética. Si pasamos a hablar de civilización, en cambio, se suele hacer referencia a realidades más cuantificables indicativas, entre otros aspectos, de un grado de desarrollo económico y técnico. Consideramos usualmente, además, que los momentos de esplendor de una realidad dada expresados en términos cuantitativos vienen acompañados de un estado no menos rico en términos cualitativos, si bien en este punto cabría, llegado el caso, preguntarse qué comprendemos por cultura y qué por estética ${ }^{1}$. Por el contrario, interrogarnos por aquello ceñido a lo cuantitativo no demanda la comprensión de la esencia del fenómeno al menos con tanta necesidad, pues bastará con tomar y estudiar una serie de datos en torno al fenómeno explorado. Pero todo esto es solo válido desde un particular enfoque.

La creación estética, vamos viendo a medida que nos desviamos de ese punto de partida, resulta más o menos ponderable en función de su valor simbólico y, únicamente después, en función de otros factores como, por ejemplo, su expresividad, su belleza o su fealdad, tan a menudo solo advertibles desde la distancia, esto es, en el momento en que somos capaces de juzgar si una expresión concreta sintetiza, realiza y modula o transforma el espíritu de una época. Desde este enfoque, podremos advertir que justamente cuestiones como la belleza o la fealdad resultan patentes cuando la forma ya se ha objetivado, cuando ya se ha fijado en torno a un aspecto de la realidad más amplio o abundante. Así, del mismo modo que ocurre en lo relativo a los modelos fisionómicos o a los diseños de muebles y vestimentas, el patrón de belleza cambia constantemente en función de coordenadas espaciotemporales, de manera que lo que en un primer momento resulta bello, con posteridad deriva hacia su opuesto y finalmente regresa al punto de partida. Lo mismo vale decir para el resto de ponderaciones aplicables a una u otra realidad.

Desde este enfoque comprendemos que el valor de la obra no reside en su belleza, en su fealdad o, por generalizar, en sus características formales, sino ante todo en su capacidad simbólica, de naturaleza cualitativa. Cercano a esto, ha de precisarse que lo que en un momento dado se ubica en la esfera del arte, en uno posterior

${ }^{1}$ Frente a lecturas más monolíticas encontramos revisiones al respecto, como por ejemplo la que a continuación recogemos de Groys, ajustada al paradigma de los tiempos recientes y desde la que un mayor poder económico no implica, ni mucho menos, un mayor grado de sublimación cultural, siendo así que el sistema económico-social tratará de ofrecer al individuo meramente sucedáneos de acelerado consumo: "Se considera que la alta cultura se acabó, porque la economía actual está dispuesta a satisfacer 'en la vida misma' todos los deseos que la alta cultura proponía satisfacer exclusivamente a un nivel simbólico. Pero si convenimos en que la 'alta cultura' opera con el deseo infinito -o, lo que es lo mismo, con el deseo de lo infinito-, la idea de que cualquier economía realmente existente puede satisfacer todos los deseos posibles, deja ver de inmediato su carácter utópico» (2008, p. 23). 
queda fuera de ella, y viceversa. Los patrones estéticos se cruzan tal y como nuestras mediciones, impregnándose de valor o futilidad en función de coordenadas relativas ${ }^{2}$. El ojo del espectador, por su parte, no deja de condensar un particular acercamiento a un espectro de realidad, pero en ningún caso su aproximación nace y muere en su mirada tal y como como si dicho espectador de un ser aislado se tratase. En la mirada del sujeto se condensan la naturaleza del objeto, la de ese mismo sujeto, la propia de la época, así como la proyectada desde otras muchas realidades periféricas.

\section{MODELOS HIPOTÉTICOS}

Tres rayas paralelas realizadas sobre un papel por un hombre mientras habla por teléfono se tiran a la basura; tres rayas encontradas sobre una pared paleolítica impregnan nuestras mentes de misterio y profundidad. Esas primeras rayas arrojadas a la basura son expuestas en un museo de ser rescatadas tres milenios después -cuando el papel ha devenido en objeto inexistente, así como la escritura-, o treinta años más tarde si la mano que las trazó es la de Pablo Picasso: en este caso, se comprende, esas tres rayas atesoran un valor simbólico, e incluso resultan aptas para valorar el estilo y el imaginario del pintor en la época en que fueron garabateadas. Una gárgola cumple una función apotropaica en el momento en que se esculpe, y una función atractiva si la observamos en nuestra época. ¿Es bella --en su sentido más superficial- una iglesia románica? No lo considerará desde tal perspectiva el orante del siglo doce, dado que su simbolismo, su verdadero valor, la precede. Este valor encubre y realza a un tiempo su realidad objetual, y sin embargo hasta nosotros podrá perfectamente llegar como reliquia dotada de belleza, y en ocasiones poco más.

Este nuevo ejemplo ofrece una nueva variante: un pasaje de una carta de Goethe se presenta como un testimonio de imponderable significación. Esas mismas palabras escritas por un enamorado a su enamorada no dejan de pasar por algo acaso admirable pero despojado del valor -y muy posiblemente de aquellas cualidades- que atribuimos al escrito de Goethe. Esto último no será así si las leemos medio siglo después y tanto el enamorado como su pareja ya hace tiempo que recogieron su Nobel. Continuaremos aún: Sófocles nos parece inatacable, un fragmento suyo, consideramos, resulta verdadero en sí mismo lo juzgue quien lo juzgue. Preguntemos a alguien de un paradigma cultural completamente ajeno e incluso-aunque todo esto tiene no pocos matices- con valores y códigos opuestos o lejanos a los expresados en las obras

2 «Todo lo transitorio es mero símbolo», llegará a señalar Spengler (2007, p. 178). El símbolo, desde su fugacidad y mutabilidad, expresa un objeto siempre ulterior. Esta cualidad simbólica, además, se ciñe sobre todo fenómeno al que se le atribuya o se le conceda una voluntad de forma, cualidad que no solo requiere de la capacidad creativa del individuo, sino que se apoya en las necesidades expresivas de una u otra cultura. El símbolo no surge mediante un acto de voluntad, sino que es fruto de un proceso orgánico. 
del ateniense. Sus piezas teatrales, en fin, alcanzan su mayor envergadura cuando son contempladas por ojos participantes, al menos en un cierto grado, del orden de ideas y códigos con los que convivió el dramaturgo. Aunque evidentemente no es preciso compartir un conjunto de valores para ponderar la calidad de una obra, rebasado un cierto límite la distancia o el desacuerdo llegan a condicionar su recepción. En este terreno sigue rigiendo una cuestión de perspectiva, dominada por tanto por relaciones de elementos y no por conceptos arraigados a valoraciones estáticas.

Un penúltimo ejemplo, tomando como base un fenómeno actual, lo hallamos en la reproducción de una obra plástica. Situémonos en la cueva segunda de Altamira, aquella construida a modo de doble de la original. Cuanto se observa nos resulta fascinante y, una vez más, bello, pero no posee el valor simbólico, estético, de la cueva original; de hecho, no posee el menor valor simbólico -o en todo caso en grado escaso, siendo incluso conveniente referirnos a este objeto desde su valor significativo, aun cuando habría que ver cómo se apreciaría pasados cinco mil años-. Por último, si mañana me regalan Las meninas, quizás pasado me ponga en contacto con el Museo del Prado, pero antes, mañana mismo, dormiré junto al lienzo: pasaré la noche en vela. Si a mitad de madrugada, no obstante, me comunican que la obra es falsa, la contemplaré veinte minutos y después me dormiré. El objeto sigue resultando igualmente hermoso, una maravilla, pero no estará dotado de valor simbólico, de belleza en su sentido más profundo.

Los ejemplos son infinitos y lo nuclear aquí reside en que en toda ponderación de un objeto, por muy logrado que nos resulte de acuerdo con nuestros patrones culturales, siempre habrá un componente simbólico que, en definitiva, es el que nos llevará a tomarlo como verdadero no en sí sino en relación con nosotros, en relación con un contexto ${ }^{3}$. Despojado el objeto de su valor simbólico, su belleza poco nos importará pues la magia, el misterio, se vendrá abajo en un solo instante: lo contemplaremos unos segundos y luego nos alejaremos sin que nada de él transforme o haga vibrar nuestra alma. Satisfará nuestros sentidos, pero no nos conmo-

${ }^{3}$ Al fin y al cabo, uno de los atributos del símbolo es su carácter ambivalente. Podemos apoyarnos aquí, en fin, en alguien tan poco dudoso de esquivar el rigor académico como Gilbert Durand, cuando en relación con la función simbólica afirma que «hace su aparición justamente cuando hay una tensión de contrarios que la conciencia no puede resolver con sus solos medios» (2007, p. 37). Poco después añade que «el simbolismo es la fuerza que pudiéramos llamar magnética, y liga entre sí los fenómenos correspondientes al mismo ritmo, permitiendo incluso su sustitución mutua» (Durand, 2007, p. 39). La función del símbolo es ante todo cohesionadora y reveladora. Solo en segundo lugar su realidad queda encubierta por atributos culturales como su belleza, fealdad, o cualquier otra categoría propia de uno u otro sistema de ideas. Asimismo, en relación con esta potencialidad para engarzar realidades, menciona Skolimowski: «Los símbolos de nuestra cultura estructuran nuestra psique, cuya estructura, a su vez, define nuestros valores, los cuales perfilan nuestra acción. Sólo en el nivel de la acción podemos describir claramente lo que está ocurriendo. La acción es la punta visible de un iceberg cuya parte oculta son nuestros valores, nuestra psique y nuestros símbolos» $(2016,285)$. 
verá. Solo el individuo superficial podrá complacerse en un objeto estético bonito o bello, si así lo queremos denominar, pero desprovisto de valor simbólico. El ojo atraído por una esencia, en cambio, podrá incluso advertir belleza, para él asociada y sometida a una verdad profunda, en un aspecto desagradable de la realidad. En este caso lo bello no queda en relación con un placer sensorial, pudiendo incluso ocurrir lo contrario, y sí, en cambio, con un estremecimiento anímico.

\section{EN TORNO AL LÍMITE Y AL SÍMBOLO}

Como es sabido, es en los límites donde andamos perdidos, donde entramos en conflicto con nuestros, en principio, más seguros valores. En lo acotado, en lo definido, se ajuste más o menos a nuestra particular verdad, no encontramos problema en manejarnos, en alzar la voz e incluso en enfrentarnos a ideas contrarias a las nuestras. Desde este terreno podremos ser rebatidos, entraremos en conflicto con otras visiones del mundo, pero difícilmente llegaremos a desequilibrarnos. Y sin embargo la realidad, no la reducción a conceptos desde la que nos aproximamos convencionalmente a ella, se mueve, se da, en los vacíos abiertos entre límite y límite ${ }^{4}$, inexistentes por lo común a nuestros ojos; abismos en los que nos vemos tan a menudo atrapados y que tanto tememos hasta el punto de, con tal de evitarlos, optar por vivir una existencia derivada, una existencia sobre conceptos ${ }^{5}$. De un modelo vital secundario a uno elemental se da un salto cualitativo, no de grado ${ }^{6}$.

${ }^{4}$ Tomamos de Eugenio Trías la siguiente consideración sobre la capacidad de abrir vacíos propia de lo liminal. Desde estos vacíos se revela la distancia entre una realidad construida, abstracta, y otra elemental. El filósofo lo argumenta desde la significación del limes -territorio donde el dominio del Imperio se desdibuja- dos mil años atrás: «El limes participaba, por tanto, de lo racional y de lo irracional, o de lo civilizado y de lo silvestre. Era un espacio tenso y conflictivo de mediación y de enlace. En él se juntaba y se separaba a la vez el espacio romano y el bárbaro. Actuaba a su vez como cópula y como disyunción. Era conjuntivo y disyuntivo. El limes, por lo mismo, impedía que el espacio de la razón se cerrara en su propia inmanencia satisfecha y que el espacio de lo extranjero invadiera, sin razón y sin ley, sin logos y sin nomos, el cercado ganado a pulso por los siglos de cultura y civilización» (2009, p. 212).

${ }^{5}$ Señala aclarativamente Földényi: «Una vez superadas ciertas fronteras, el afán de comprender y de saber se vuelve ilimitado y se plasma en la imposibilidad de definir nada. Allí se descubre que la verdad no significa la exactitud de una afirmación; de este modo, el ser humano sólo demuestra su respeto a las fronteras. Manteniéndose dentro de éstas, el hombre se esconde ante otra suerte de verdad que sólo se desvela cruzándolas. En la verdad de las correspondencias, la verdadera naturaleza de su vida cae en el olvido; olvida que su vida no puede compararse con nada, que no existe nada a lo que pueda subordinarse y que hasta las afirmaciones relativas a la vida son falsas y nulas por la singularidad de ésta» (2008, p. 345).

${ }^{6}$ Queda, además, ceñido a este regreso a lo elemental, la preponderancia que el término de 'cuaternidad' adquiere en el siglo xx. Heidegger lo trata desde su capacidad para posicionar, 
Samuel Huntington, al inicio de El choque de civilizaciones, realiza un recorrido por el estado de la cuestión en torno a términos como 'civilización' o 'cultura'. Tras exponer por qué comprende la civilización como una «entidad cultural» $(2015$, p. 46) desarrolla convincentemente su afirmación para, por último, señalar que la interpretación que él mismo defiende es la dominante en todas las latitudes excepto en Alemania7. Líneas después, menciona que «algunos antropólogos han invertido incluso la relación, concibiendo las culturas como características de sociedades primitivas, inmutables, no urbanas, mientras que las sociedades más complejas, desarrolladas, urbanas y dinámicas serían civilizaciones» (Huntington, 2015, p. 46). Por último, da la razón a Braudel cuando este afirma que tal distinción se presenta engañosa. Para el historiador de Annales, «culture et civilisation ne sont donc pas séparées. Culture ou civilisation ne signifie pas disjonction mais interchangeabilité. Cette définition lui permet d'échapper à la dichotomie matière/esprit, toujours manifeste dans la distinction allemande entre Kultur et Zivilization» (Cotesta, 2006, p. 106) ${ }^{8}$.

De acuerdo con la dialéctica expuesta en el punto anterior, se puede adivinar que el hecho de que, siendo efectivamente parcial la definición rebatida por Huntington-como lo es todo sistema de ideas a poco que se eleve un tanto de la tierra y se desarrolle al margen de la realidad-, resulta práctica a la hora de establecer estratificaciones siempre que no nos enredemos en sutilezas conceptuales y no empleemos nuestra retórica como pretexto para apoyar sobre las distinciones aludidas cuestiones marcadamente ideológicas -tal y como, casi inevitablemente, acaba por ocurrir-. Esto es, resulta útil siempre que nos valgamos de dicha terminología para entendernos y no para atacar aspectos periféricos o paralelos. En este caso, sin embargo, parece patente que la historiografía anglosajona y la francesa se enfrentan

para asentar. Exponemos una consideración al respecto que conserva el sentido poético con que el filósofo impregna su pensamiento: «Cuidar la Cuaternidad, salvar la tierra, recibir el cielo, estar a la espera de los divinos, guiar a los mortales, este cuádruple cuidar es la esencia simple del habitar. De este modo, las auténticas construcciones marcan el habitar llevándolo a su esencia y dan casa a esta esencia» (1994, p. 140). Conforme a la idea de totalidad que atesora el 'cuatro' (Chevalier, 1986, pp. 380-384), el filósofo reintegra el lugar del ser no en un orden conceptual sino en uno primordial. Podemos asimismo remitir a Gadamer desde su insistencia en el valor del lenguaje poético -frente al cotidiano- como asentador del ser (2006, pp. 73-80). La palabra poética, siendo ella misma raíz, enraíza al individuo.

7 Arguye Huntington que «los pensadores alemanes decimonónicos establecieron una neta distinción entre 'civilización', que incluía la mecánica, la tecnología y los factores materiales, y 'cultura', que incluía los valores, los ideales y las más altas cualidades intelectuales, artísticas y morales de una sociedad» (2015, pp. 46).

${ }^{8}$ Con ello se llega, además, a otro de los motivos nucleares que, aunque no abordado en estas páginas, se advierte como problema de fondo de la oposición indicada. Nos referimos a la primacía de una cosmovisión monista frente a una dualista, lo que en último término tiende a suponer una cosmovisión inmanente frente a una trascendente. 
conjuntamente a la alemana dados los factores precisamente ideológicos arraigados a cada una de ambas perspectivas.

Al respecto, un concepto a nuestro juicio axial a la hora de comprender una cultura como es el de voluntad estética o voluntad de forma, relativo a la capacidad simbólica que posee un objeto determinado, remite a la historiografía cultural -y social- propiamente alemana. A modo de puerta de entrada a la significación de este término, baste con indicar que Worringer, a partir de Riegl, menciona que "por 'voluntad artística absoluta' hay que entender aquella latente exigencia interior que existe por sí sola, por completo independiente de los objetos y del modo de crear, y se manifiesta como voluntad de forma. Es el 'momento' primario de toda creación artística; y toda obra de arte no es, en su más íntimo ser, sino una objetivación de esta voluntad artística absoluta, existente a priori» (1997, pp. 23). Esta voluntad de forma definidora de toda cultura, hablando en este caso desde los planteamientos de la tradición alemana, permanecerá inexistente o apenas desarrollada en la esfera, tomada en abstracto, del concepto 'civilización', encauzada a la consecución de fines orientados hacia lo utilitario y lo artesanal.

Si recogemos esta interpretación en este momento es justamente con el deseo de atenuar sus rasgos y destacar la posibilidad de comprender lo artesanal como un puente entre lo mecánico y lo creativo, entre lo artificial y lo conformador de símbolos -tomando esto último con cautela, esto es, meramente en atención a su carácter orgánico-. No cabe en este sentido dudar de que incluso objetos eminentemente utilitarios pueden perfectamente acompañarse de atributos simbólicos. Aun cuando, siguiendo a Pareyson, podríamos comprender que: «El arte genuino no se somete a eso que hoy llamamos 'consumo' sino a la 'contemplación' que el activismo cada vez más generalizado parece olvidar» (1986, pp. 21), cabe añadir que no es preciso separar tajantemente entre objetos capaces de realizar una función y aquellos otros que despiertan admiración contemplativa, en la medida en que esto último depende no tanto del objeto en sí, sino del modo en que el sujeto interactúa con dicho objeto.

Cercano aún a este motivo queda la realidad del objeto como fenómeno esquivo a su encorsetamiento por rígidas abstracciones. En el momento en que esta entidad trasciende criterios clasificadores $-y$ recordemos que dicha cualidad se presenta como un atributo cambiante y, por tanto, plausible de ser atesorado por cualquier objeto- ofrece resonancias de otro modo eclipsadas. El hecho de que por nuestra parte entendamos como simbólico o como meramente significativo a uno u otro objeto, poco incidirá en su capacidad para crear mundo, pues esta capacidad, ha de comprenderse, se genera a sí misma y nosotros lo más que podemos hacer es participar de su potencialidad. En este sentido, Lefebvre no duda en señalar que "La obra que nace de una creación trasciende la representación y la significación, la filosofía y la teoría. Únicamente la obra [...] crea un sentido» (2006, p. 118). Lo 
crea, pero no es suficiente su 'estar ahí', sino que junto a ello ha de activarse, ha de ser 'puesto ahí'. Todo ello, por tanto, debe ser ponderado sin olvidar que, dado que convivimos con diferentes sistemas de valores y ordenamientos eidéticos, lo que para una entidad cultural posee un valor simbólico -como nexo de unión entre concreciones e idealidades-, para otra no deja de ser un fenómeno, dicho en los términos anteriormente mencionados -que ahora nos parecen un tanto estrechos o groseros-, de civilización.

En último término, tomando como referente las palabras de Skolimowski, habría que distinguir entre símbolos de menor o de mayor duración desde los que realizar nuevas estratificaciones -útiles, pero siempre relativas-: "La invención de nuevos símbolos, apropiados para un periodo concreto, es una tarea muy difícil. Aun así, la vida encuentra el modo de hacerlo. Continuamente concebimos símbolos que luego se aprueban en la vida real. Algunos desaparecen pronto; otros muestran una viveza y una notable capacidad para inspirar la imaginación humana: éstos son los que permanecen» (Skolimowski, 2016, pp. 272). Así pues, la situación del símbolo como objeto nuclear posibilita la consolidación de un ordenamiento cultural, si bien solo de darse las condiciones convenientes, dado que en la formación de esferas de ideas inciden aspectos que escapan a las demandas inmediatas del objeto y del sujeto.

Dejando de lado lo útil de los modelos clarificadores de la historiografía alemana, la opinión preponderante hoy, dada la nivelación por la base con la que convivimos y que sin embargo comprendemos como necesario punto de partida de un reordenamiento simbólico -aun cuando todo ello deviene en situación dañina de mantenerse por un tiempo prolongado-, remite a la innecesidad de distinguir civilización y cultura por motivos, primeramente, de homeostasis cultural en un mundo que se reorganiza a escala masiva. En este sentido, la propuesta de Lefebvre de situar en el centro a la propia creación parece un modelo conveniente con vistas a eludir disputas ideológicas. Con cierta precaución podemos comprender que, aislando dicho objeto de nuestras ciegas fijaciones, se presenta como fenómeno capaz de cohesionar distintas perspectivas o comprensiones de la realidad. Podría decirse que la distinción entre civilización y cultura queda en este sentido disuelta, y, sin embargo, como hemos advertido, aquí nos encontramos con un nuevo escollo en lo tocante a nuestra situación actual dado que donde Lefebvre advierte un símbolo, nuestra sociedad solo es capaz de apreciar un objeto sin más y, en último término, una nada.

Puede afirmarse, en suma, que despojados de un orden de ideas envolvente lo simbólico no tiene lugar en nuestro paradigma por resultar ineficiente, innecesario. La inexistencia de un orden simbólico de largo alcance, circunstancia con la que convive Occidente sin la menor preocupación y que viene emparejada al eclipse del aludido orden eidético, nos pone, necesaria y reveladoramente, ante la situación amarga de formar parte de una sociedad altamente desencantada -en los 
términos expuestos por Taylor- ${ }^{9}$, escéptica y, sin embargo, o justamente por ello, tremendamente idólatra. El asunto por momentos parece paradójico, en tanto que, como animales simbólicos ${ }^{10}$, constantemente buscamos realidades vivientes, espiritualizadas 0 , si vacilamos a la hora de apuntar tan alto, dinámicas ${ }^{11}$, siendo así que nos vemos obligados, si queremos respirar, si deseamos escapar de nuestro corsé racional, a ahondar, a aventurarnos y a descubrir nuevos valores en culturas en ocasiones lejanas, todo ello a modo de contrapeso de lo experimentado en nuestro lastrado y marchito paradigma, tan recargado de conceptos e historia como vacío de fundamento y de contenido -saturación de significados y nihilismo caminan a la par- ${ }^{12}$. Según vamos viendo, frente al ya aludido riesgo que supone todo exceso de fijaciones abstractas, una carencia de ellas conlleva asimismo el riesgo de vaciar de contenido y sentido todo objeto y realidad.

\section{SINCRETISMO}

Todavía en relación con estos aspectos, cabe añadir que la porosidad, maleabilidad y capacidad metamórfica de culturas menos estructuradas, menos solidificadas, nos permite participar -aun en grado menor-de sus experiencias espirituales con solo adaptarlas en cierto grado a las nuestras, consistiendo este proceso de adaptación, por lo común, en una mercantilización de experiencias simbólicas o sacras. Pero al mismo tiempo a nadie se le escapa que el fenómeno de colonización -que es siempre bidireccional, destacándose un sentido u otro en función del aspecto que se observe- que se da en este desarrollo, aun cuando ilumina un eclipse simbólico, perfectamente es capaz de prefigurar un próximo y renovado, sincrético

9 Señala Charles Taylor que «el proceso de desencantamiento [...] puede leerse como la pérdida de una cierta sensibilidad que constituye un empobrecimiento real (a diferencia de la mera remoción de sentimientos irracionales» (2015, p. 52). El autor asimila el desencantamiento, además, a la pérdida de magia en la relación del sujeto con el mundo, en su visión y sentido del mundo.

10 De nuevo Skolimowski, siguiendo a Cassirer, recuerda que: «La creación, percepción y sensibilidad para los símbolos es una prerrogativa de la condición humana» (2016, p. 283).

11 «El proceso simbólico es como una corriente unitaria de vida y pensamiento que surca la conciencia produciendo en ese móvil flujo la multiplicidad y cohesión, riqueza, continuidad y constancia de la conciencia» (Cassirer, 2003a, p. 239).

12 Sobre el apoyo que proporciona Cassirer a partir de uno de los presupuestos rectores de su Filosofía de las formas simbólicas, cabe exponer que la necesidad de fundamentar la existencia implica a un tiempo la expresión del fundamento del ser. Recogiendo sus palabras, leemos: «El dualismo metafísico parece salvado en la medida en que pueda mostrarse que precisamente la misma función pura de lo espiritual debe buscar en lo sensible su realización concreta, pudiéndola hallar, en última instancia, solamente aquí» (2003b, p. 28). Este fundamento del ser queda expuesto mediante el símbolo en el orden de lo sensible. 
asimismo, renacimiento. Para ello es preciso que el engarce de aspectos culturales propios de diferentes tradiciones acontezca orgánicamente en un proceso de pseudomorfosis relativo a la emergencia de nuevos contenidos en consolidadas formas. Esto puede acontecer, a fin de cuentas, dada la naturaleza misma del símbolo y por tanto del objeto, capaz de arraigar y metamorfosearse allí donde encuentre un óptimo terreno donde asentarse.

Regresando a nuestro punto de partida, una vez expuestos los obstáculos advertibles a la hora de recomponer este cuadro, encontramos que una distinción entre cultura y civilización, pudiendo resultar válida para satisfacer nuestra sed de categorías, se presenta puntualmente ineficaz a la hora de esquematizar nuestra época presente, dado que no dejamos de movernos, de modo masivo, en incipientes estratos simbólicos, estratos donde lo indistinto y lo confuso campean libremente a la espera de un fermento que permita el desarrollo de una u otra idealidad. Es por ello preciso que el sistema se recomponga a partir de sincretismos que paulatinamente arraiguen, de modo tal que tarde o temprano, a medida que una nueva síntesis de elementos acontezca -esto solo puede ocurrir orgánicamente-, la pluralidad que hoy da forma a nuestro imaginario quede reformulada sobre renovados moldes.

En lo relativo a este hecho, además, comprendemos que en este proceso de resimbolización tan solo acaban germinando aquellos elementos que mejor arraigan en asentados patrones sociobiológicos ${ }^{13}$, mientras que resultan inútiles aquellos que no encajan óptimamente en las estructuras, en este caso, de acogida. Solo tras el asentamiento de nuevas realidades un orden simbólico puede comenzar a

${ }^{13}$ La necesidad de fundir cultura y biología, más acusada en nuestra época a medida que se precisa de ella para refundamentar y resimbolizar lo real, encuentra uno de sus más firmes bastiones en la obra de Walter Burkert. De esta destacamos las siguientes citas, orientadas a apuntalar la convivencia entre ambas áreas -cultura y biología-. Esta imbricación resulta especialmente urgente por los motivos que exponemos al término de esta nota, así como en la siguiente: "Se ha llegado a atacar el concepto mismo de naturaleza humana. En lo que se ha denominado 'nuevo dualismo', la naturaleza es excluida de los estudios culturales. Los seres humanos son definidos por la cultura mucho más allá de su constitución natural: 'no hay naturaleza humana aparte de la cultura'» $(2009$, p. 17). Más adelante leemos la siguiente exhortación, relativa a que: "Los estudios culturales deben fundirse con la antropología general, que finalmente se integra en la biología» (Burkert, 2009, p. 27). Por último, destacamos una reflexión que nos sitúa en el umbral de los estudios actuales: «La hipótesis básica de la sociobiología es la 'coevolución de los genes y la cultura', con una retroalimentación constante entre ambos» (Burkert, 2009, p. 30). Dando un paso más, Francis Fukuyama, como seguiremos viendo de inmediato, no deja de aludir a la imposición de la genética sobre la cultura a la hora de determinar las posibilidades y, en suma, la naturaleza del individuo: «Durante gran parte del siglo $\mathrm{xx}$ las ciencias naturales, y en particular las sociales, tendieron a conceder especial relieve a los motores culturales del comportamiento, en detrimento de los naturales. El péndulo ha vuelto a retroceder -algunos afirman que demasiado- en los últimos años para decantarse hacia las causas genéticas» $(2002$, p. 42). 
florecer, momento en que acaso resulta conveniente una estructuración conceptual más precisa llamada a distinguir, siempre con cierta cautela, lo funcional de lo eidético. Tampoco hemos de olvidar que, aun exponiéndose este fenómeno desde nuestro punto de vista, la unidad cultural dominante viene a identificarse con aqueIla que cuenta con una mayor vitalidad no ya o no solo en sus estratos superficiales sino, ante todo, en sus profundidades y raíces ${ }^{14}$. Dejando de lado esto último, cabe añadir que, a medida que nuevas formalizaciones simbólicas van emergiendo, conviene que el sujeto tome las entidades eidéticas resultantes como construcciones lógicas, pero no como primeras realidades, todo ello con el fin de evitar su incorporación a una nueva y rígida dialéctica cultural. En todo este proceso, hasta que dicha fusión no se formaliza, el individuo ha de convivir con realidades sincréticas no armonizadas orgánicamente y absorbidas por un demonio mercantil en el que técnica y capitalismo se presentan fraternalmente abrazados.

Por último, si ponemos todo ello más directamente en relación con nuestra vivencia actual, no está de más recalcar que todo ello solo se sostiene desde un patrón socio-cultural hasta hace poco indiscutible, realidad que hoy ponemos en duda a medida que, como explora y alerta Fukuyama -por tomar un nombre representativo-, el ser humano pierde su identidad en favor de lo que, a grandes rasgos, ha de situarse en la esfera del posthumanismo. En esta encrucijada permanece activa la siguiente consideración de Agamben, quien nos presenta a Heidegger como revelador de la presente bifurcación desde premisas fundamentales en lo concerniente a su grado, rotundo, de elementalidad: «En este punto hay dos escenarios posibles desde el punto de vista de Heidegger: a) el hombre post-histórico no es ya el custodio de la propia animalidad en cuanto irrevelable, sino que trata de gobernarla y de hacerse cargo de ella mediante la técnica; b) el hombre, el pastor del ser, hace suya su propia latencia, su propia animalidad, que no queda encubierta ni es convertida en objeto de dominio, sino que es pensada como tal, como puro abandono» (2010, p. 102).

Según lo hasta ahora expuesto, y volviendo a un terreno algo más estable, más allá de una guerra conceptual en torno a lo que comprendemos por cultura y por

${ }^{14}$ Frente a la visión de Huntington, atenta, entre otros factores, al despertar de la civilización China, Fukuyama sitúa la emergencia de nuevos contenidos potencialmente conflictivos en relación con aspectos que trascienden las categorías hasta hace poco manejadas y que, en línea con la visión hoy dominante, localiza el campo de acción de estas fuerzas en el ámbito del posthumanismo. El politólogo se expresa desde la incertidumbre en El fin del hombre, con comentarios significativos en lo que aquí nos ocupa: «El mundo posthumano podría ser mucho más jerarquizado y competitivo que el actual, y por lo tanto podría estar plagado de conflictos sociales. Podría ser un mundo en el que se haya perdido el concepto de 'humanidad común', porque habremos mezclado nuestros genes con los de tantas otras especies que ya no tendremos una idea clara de lo que es el ser humano» (Fukuyama, 2002, p. 345). Con esta visión la realidad cultural parece quedar por completo soterrada. 
civilización, cuanto sobresale en esta problemática es el casi vacío simbólico con el que el sujeto occidental convive a día de hoy. Este vacío, inevitablemente según nos lo enseña la historia, comienza a verse desplazado por valores y objetos propios de paradigmas hasta hace poco comprendidos en los antípodas de nuestro imaginario al menos en sus formas y funciones aparentes. Aquello que se advierte puede entenderse como un proceso de ósmosis o, como ya se ha indicado, de mutua colonización, de absorción por parte de nuestro imaginario de una serie de elementos tenidos como periféricos y, a un mismo tiempo, como un proceso de proyección por parte de civilizaciones/culturas más versátiles y activas de su particular patrimonio estético, cultural, religioso y, no puede ser de otro modo, mercantil-económico. El modo más o menos conflictivo en que se realiza el proceso, y lo que resulta de ello, queda fuera de nuestro campo de visión, como evidentemente las aún confusas posibilidades del posthumanismo, algunas de cuyas derivas las recoge Antonio Diéguez en su reciente trabajo Transhumanismo, a cuya lectura remitimos.

Llegados a este lugar conviene apuntar que, si bien el interés que podemos mostrar por cuanto nos llega de sociedades culturalmente distantes ocupa en un primer momento un espacio superficial en nuestras vidas, no ocurre lo mismo cuando, como en el caso que hoy conforma nuestra realidad cotidiana, dichas sociedades consolidan un marco económico poderoso y en innegable expansión. En tales ocasiones su adentramiento y sincretismo acontece con inusual rapidez, ante todo si los elementos en este caso ajenos cohesionan adecuadamente con aquellos otros situados en las raíces de nuestro sistema ${ }^{15}$, aquellos que hemos advertido altamente dañados pues están, literalmente, desenraizados. En estos casos la presión resulta tan exuberante que dichas fuerzas comienzan de inmediato no solo a presionar sino asimismo a coagular en las estructuras de nuestro orden social en forma de un negocio a gran escala llamado a impregnar, desestabilizar, suplantar, así como, en lo que toca a los contenidos arrastrados por dicha dinámica, a enriquecer y, en general, a dinamizar nuestro imaginario. Y es que la inoculación de un sustrato simbólico camina de la mano del movimiento de reorganización de un global cúmulo de fuerzas, comprendiéndose el imaginario emergente y el degradado como engranajes paralelos sin los cuales no sería posible ninguna dinámica histórica.

\section{INFLACIÓN Y DEVALUACIÓN SIMBÓLICA}

A raíz de lo expuesto y volviendo a nuestro motivo inicial, podríamos erróneamente comprender que, como si de una relación causal se tratase, un exceso de

${ }^{15}$ Lo podemos encontrar, por poner un ejemplo cotidiano, en el poso que espiritualidades orientales, de la mano de un eficaz nutriente económico, dejan ya en nuestra cultura, sincretizándola al tiempo que revitalizándola. 
sedimentación cultural derivará exclusivamente y sin límite alguno en una mayor densidad simbólica, y sin embargo esto no es así en tanto que el símbolo se caracteriza por requerir de un dinamismo, de una renovación constante enemiga de todo estado de reificación. En función de cuanto hemos podido explorar en el epígrafe anterior, es decir, conforme a la retroalimentación entre factores económicos y utilitarios, y construcciones / ponderaciones simbólicas, cabe entender que una cultura sometida a un alto grado de abstracción y sustentada por una notable pujanza económica tenderá, en su inflación, a cerrarse en alto grado sobre sí misma, derivando todo ello -pues no encontrará otro modo de sustentarse- en un vaciamiento simbólico. Llegado el caso, los elementos simbólicos de dicha cultura, en consonancia con su aludida adquisición de poder, comenzarán paulatinamente a reificarse, las estructuras devendrán a cada momento más sólidas, si bien en un primer instante sustentadas todavía por una base económica que todo lo sostendrá. Solo a la larga, cuando muchas de estas estructuras se muestren ineficaces con vistas a incorporar contenidos ajustados al nuevo orden de $\operatorname{cosas}^{16}$, comenzará a percibirse la pérdida de sentido padecida por una entera sociedad y a intuirse con ello la caída de una completa unidad cultural.

Los símbolos, oxidados, devendrán entonces en alegorías, imágenes sin sustancia. El vacío dejado tras su decaimiento concentrará una carga energética de exactamente igual magnitud a la que antes atesoraba el espectro simbólico, si bien de signo opuesto ${ }^{17}$. El siguiente paso será, no puede ser de otro modo, la desintegración de dicha unidad cultural y la fagocitación de la misma por un nuevo imaginario introducido e incorporado al compás que se alzan nuevas realidades económicas. Puede hablarse, según vamos viendo, de un orgánico y paulatino proceso de metamorfosis. En este recorrido, el estado de hipertrofia cultural desde el que habíamos partido habrá ido dando paso a un apagamiento simbólico: lo que antes resplandecía y se creía con derecho a ser mostrado al mundo es tomado ahora, dado su vaciamiento eidético y sustancial, como elemento residual; y es que, regidos por un mismo mecanismo, el sistema ahora al alza se creerá llamado a civilizar

${ }^{16} \mathrm{Ha}$ de tenerse en cuenta, conviene aclarar, que en procesos como el aquí explorado muchas de las estructuras previas a la metamorfosis simbólica devendrán culturalmente ineficaces -de modo que acabarán, en suma, por ver resquebrajadas sus paredes-, mientras que otras tantas se perpetuarán al resultar aptas para -con especial sutileza- ir incorporando novedosos contenidos.

17 La potencialidad del símbolo queda anulada en el momento en que se incorpora a una entidad estática. El símbolo pierde sus cualidades en el instante en que se incorpora al lenguaje de la historia. Podemos sintetizar esto último desde la realidad del Logos como motivo mitológico de vida y apagamiento. Se trata de un motivo enteramente vinculable con lo aquí expuesto. El símbolo, una vez que es incorporado a la historia, pierde su valor fundamental, sea este símbolo representado mediante el lenguaje, mediante la imagen, o mediante cualquier otra entidad: toda entidad expresiva puede constituirse tanto en una entidad liberadora como, desde un uso inadecuado de la misma, en un mecanismo coercitivo. 
al claudicante hasta que, finalmente, aquel primero se sabe inefectivo no solo a ojos ajenos sino asimismo a los suyos propios. Un apunte: allá donde indicamos 'al alza y 'claudicante', históricamente han venido a designarse los factores actuantes desde las categorías de 'civilizador' y 'bárbaro' respectivamente-siempre desde la mirada y el juicio, claro está, del primero de ambos factores-. En base a esta categorización, sin duda, al sujeto individual y colectivo le resulta más sencillo justificar moralmente lo que, desde una perspectiva neutra y hasta en exceso aséptica, podría advertirse como un dinamismo afín a la tectónica de placas.

Lejos por todo ello de darse un estado nivelado entre civilización, cultura y riqueza simbólica, estos factores flirtean y pugnan entre sí, de modo tal que el símbolo se ve sometido a esas mismas fuerzas económicas que en un primer momento permitieron su asunción. De todo esto, cabe añadir sin profundizar en ello, se extrae el que podemos fácilmente hallar mayor densidad simbólica en una sociedad a nuestros ojos -contaminados por mediciones económicas- técnicamente atrasada, que en una altamente desarrollada, en la medida en que, en el caso de estas últimas, esto es, en el de sociedades desvinculadas de su fundamento, rige primeramente el usufructo y el fluctuante valor de mercado. Es justamente en este lugar donde cabe recordar una vez más a Luigi Pareyson en su crítica a una sociedad eminentemente utilitarista. Afirma al respecto el filósofo que: «Es natural que el consumo destruya su objeto, ya que su característica esencial es la aniquilación con el ejercicio del goce de aquello que se está disfrutando. Se trata de un disfrute impaciente y voraz, que no tiene otra finalidad que este ejercicio, negando el propio objeto en el mismo momento que lo posee» (1986, p. 21). En línea con lo dicho, no vinculamos la problemática aquí expuesta con el mero uso, a nuestros ojos no necesaria e imperativamente negador de la función simbólica, sino con lo que Pareyson denomina "disfrute incipiente y voraz», lo que hace alusión tanto a un aspecto de grado como de modo o clase. En relación con esto último, el uso que el sujeto hace del objeto, no participando de aquel cuidado al que hace referencia Heidegger en el comentario páginas atrás recogido -y que hay que poner en relación con cuestiones ecológicas-, mata definitivamente el valor del objeto y a nosotros con él en tanto que nuestra realidad pierde progresivamente un grado tras otro de ser.

La ecuación spengleriana, vemos ahora, se invierte fácilmente, y sin embargo, reiteramos, no deja de resultar válida en un momento de equilibrio económicosimbólico o, al menos, no exageradamente desproporcionado. La presente relación parece inadecuada, por contra y según acabamos de indicar, en aquellos momentos en que alguno de los factores aludidos alcanza su paroxismo, y su más aguda consecuencia la formula Benjamin cuando señala que 'no existe nunca un documento de la cultura que no sea al mismo tiempo uno de la barbarie': «Es ist niemals ein Dokument der Kultur, ohne zugleich ein solches der Barbarei zu sein» (1955, p. 498). 


\section{CONCLUSIONES}

Según lo expuesto en estas páginas, en lugar de comprender los términos estudiados -cultura y civilización- desde una serie de cualidades triunfalistas tomadas como cotas máximas de nuestra identidad, podemos ponerlos en relación con más neutras ponderaciones $y$, en algunos o en tantos aspectos, incluso con atributos desvalorizadores. Así, en sentido opuesto al preconizado por Spengler, resulta posible adjudicar a tales conceptos, en sus estadios de hipertrofia, un atributo negativo en relación con la paralela necesidad por parte de una concreta cultura de alimentar la propia identidad sin atención a los medios y al modo en que lleva a cabo esta 'tarea'.

Hemos observado, cercano a ello, cómo en aquellos momentos en que una devaluación simbólica aboca a un conjunto social a un estado de relativismo, dicha esfera cultural se ve progresivamente desplazada como resultado del ejercicio de colonización más o menos orgánico que sufrirá dentro de un proceso de propiedades homeostáticas en el que unos y otros actuantes desarrollan sus papeles como si de un mecanismo ciego dirigiese sus acciones.

¿Civilización, cultura, barbarie? Lo simbólico, para nuestra esperanza, desborda tal terminología, aun cuando hoy apenas encuentra su sitio en nuestro imaginario. Aquello que hemos querido mostrar a lo largo de estas líneas es una lógica de fuerzas desde la que no es posible sino comprender cada una de las entidades y dinámicas exploradas como cohabitantes de un global ordenamiento. Cada una de ellas tiende a exponer sus demandas por medio de conceptualizaciones desde las que la conciencia de la sociedad que así se expresa queda a salvo, aun cuando esta valoración se modifica en cuanto se realiza desde una diferente perspectiva.

\section{REFERENCIAS BIBLIOGRÁFICAS}

Agamben, G. (2010). Lo abierto. El hombre y el animal. Valencia: Pre-textos.

Benjamin, W. (1955). Schriften II. Frankfurt: Suhrkamp.

Burkert, W. (2009). La creación de lo sagrado. La huella de la biología en las religiones antiguas. Barcelona: Acantilado.

Cassirer, E. (2003a). Filosofía de las formas simbólicas I. México D. F.: Fondo de Cultura Económica.

Cassirer, E. (2003b). Filosofía de las formas simbólicas III. México D. F.: Fondo de Cultura Económica. 
Chevalier, J. (1986). Diccionario de símbolos. Barcelona: Herder.

Cotesta, V. (2006). Images du monde et société globale. Grandes interprétations et débats actuels. Canada: Les presses de l'Université Laval.

Durand, G. (2007). La imaginación simbólica. Buenos Aires: Amorrortu.

Földényi, L. (2008). Melancolía. Barcelona: Galaxia Gutenberg.

Fukuyama, F. (2002). El fin del hombre. Consecuencias de la revolución biotecnológica. Barcelona: Ediciones B.

Gadamer, H.-G. (2006). Estética y hermenéutica. Madrid: Tecnos.

Groys, B. (2008). Obra de arte total Stalin. Valencia: Pre-Textos.

Heidegger, M. (1994). Conferencias y artículos. Barcelona: Ediciones del Serbal.

Huntington, S. P. (2015). El choque de civilizaciones y la reconfiguración del orden mundial. Barcelona: Paidós.

Lefebvre, H. (2006). La presencia y la ausencia. México, D. F.: Fondo de Cultura Económica.

Pareyson, L. (1986). Conversaciones de estética. Madrid: Visor.

Skolimowski, H. (2016). La mente participativa. Mas Pou (Girona): Atalanta.

Spengler, O. (2007). La decadencia de Occidente. Tomo I. Bosquejo de una morfología de la historia universal. Madrid: Austral.

Taylor, C. (2015). Encanto y desencantamiento: secularidad y laicidad en Occidente. Bilbao: Sal terrae.

Trías, E. (2009). Creaciones filosóficas I. Ética y estética. Barcelona: Galaxia Gutenberg / Círculo de Lectores.

Worringer, W. (1997). Abstracción y naturaleza. Madrid: Fondo de Cultura Económica. 